\title{
Elevated Platelet Distribution Width Predicts Poor Prognosis in Gallbladder Carcinoma
}

\author{
Fei Liu* \\ Hai-Jie Hu* \\ Parbatraj Regmi \\ Yan-Wen Jin \\ Wen-jie Ma $\mathbb{D}$ \\ Jun-Ke Wang \\ Rui-Qi Zou \\ Fu-Yu Li iD \\ Department of Biliary Surgery, West \\ China Hospital of Sichuan University, \\ Chengdu, 6I004I, Sichuan Province, \\ People's Republic of China \\ *These authors contributed equally to \\ this work
}

Correspondence: Fu-Yu Li

Department of Biliary Surgery, West

China Hospital of Sichuan University,

Chengdu, 6I004I, Sichuan Province,

People's Republic of China

$\mathrm{Tel} / \mathrm{Fax}+8602885422465$

Email lfy_74@hotmail.com
Background: Previous studies have demonstrated that platelet distribution width (PDW) is a reliable predictor of prognosis of a variety of tumors. Nevertheless, the prognostic value of PDW in gallbladder carcinoma (GBC) remains unknown. We aimed to explore the correlation between PDW and prognosis in patients with GBC.

Methods: A total of 303 patients with GBC who underwent curative surgery between January 2005 and February 2017 were enrolled. The relationship between PDW and clinicopathological features was analyzed. Receiver operating characteristic (ROC) curve was used to identify the optimal cutoff value of PDW. The overall survival (OS) rate was estimated by Kaplan-Meier method. Meanwhile, univariable and multivariable Cox regression model were used to evaluate the risk factors for OS.

Results: There was significant correlation between elevated PDW and AJCC stage. In addition, survival analysis revealed that the patients with $\mathrm{PDW}>14.95$ have a worse prognosis than patients with PDW $\leq 14.95$ ( $\mathrm{P}<0.001)$. The multivariable Cox regression model analysis demonstrated that PDW was an independent prognostic factor in GBC patients (hazard ratio=1.976, 95\% confidence interval:1.474-2.650, $\mathrm{P}<0.001$ ).

Conclusion: Elevated PDW can predict poor prognosis in GBC patients, and further studies are needed to verify the reliability and clarify the exact molecular mechanistic of PDW in GBC.

Keywords: gallbladder carcinoma, platelet distribution width, prognosis

\section{Introduction}

Gallbladder carcinoma (GBC) is the most common malignancy of the biliary tract. ${ }^{1}$ Curative resection is currently effective therapeutic option for GBC patients. ${ }^{2,3}$ Despite advances in diagnosis and treatment, the 5-year overall survival (OS) rate of GBC still remains poor. ${ }^{4,5}$ Furthermore, the recurrence rate of GBC is high, and it is insensitive to chemotherapy and radiotherapy. ${ }^{6}$ Thus, identifying novel biomarkers is clinically urgently needed for improving tumor management.

Previous studies have shown platelets are related to tumor development, progression, and metastasis. $^{7-9}$ There is evidence that activated platelets mediate tumor growth, invasion, aberrant angiogenesis, and metastasis. ${ }^{10,11}$ Recently, several studies have demonstrated that high platelet counts are associated with poor prognosis in gastric cancer, pancreatic cancer, colorectal cancer, renal cell cancer, and ovarian cancer. ${ }^{12-16}$ In addition, it also has been reported that elevated platelets are related to a poor prognosis in GBC patients. ${ }^{17}$ However, total platelet count is determined by the production and consumption of platelets. Owing to the normal compensatory mechanism of the body, a normal platelet count can mask the presence of hypercoagulable states and 
pro-inflammatory cancer phenotypes. ${ }^{18}$ Conversely, platelet distribution width (PDW) reflects changes in platelet size and further reflects platelet activity. ${ }^{19} \mathrm{PDW}$ is associated with the prognosis of various types of cancer, such as pancreatic adenocarcinoma, hepatocellular carcinoma, and colon cancer. ${ }^{20-22}$ However, whether PDW is associated with the prognosis in GBC has not been well defined.

The purpose of this study was to explore the prognostic influence of the PDW on the survival of GBC patients.

\section{Methods}

\section{Study Population}

We retrospectively analyzed 303 patients with GBC who underwent curative surgery at West China Hospital of Sichuan University between January 2005 and February 2017. All final diagnoses were confirmed by pathologic examination. No patients accepted neoadjuvant chemotherapy before the curative surgery. The curative surgery was defined as R0 or R1 resections. ${ }^{23}$ The clinicopathohistological data were collected through medical records, including age, gender, cholelithiasis, total bilirubin (TB), alanine aminotransferase (ALT), aspartate transaminase (AST), albumin (ALB), white blood cell count (WBC), platelet (PLT), platelet distribution width (PDW), neutrophil-to-lymphocyte ratio (NLR), platelet-tolymphocyte ratio (PLR), prognostic nutritional index (PNI), carbohydrate antigen 19-9 (CA19-9), carcinoembryonic antigen (CEA), pre-operative biliary drainage, surgical procedures, incidental GBC, lymphadenectomy, the number of retrieved and positive lymph nodes, vascular invasion, perineural invasion, tumor differentiation, $\mathrm{T}$ stage, $\mathrm{N}$ stage, margin status, American Joint Committee on Cancer (AJCC) stage, and postoperative adjuvant therapy. The measurement of serum parameters was performed within one week before the operation. The classification of the 7th edition of TNM was used in proper to AJCC recommendations on the staging of GBC. In our study, WBC, PLT, and PDW were determined with XE2100 and XE-5000 systems (Sysmex Corporation, Kobe, Japan). TB, ALT, AST, and ALB was determined with a cobas 8000 analyser (Roche, Mannheim, Germany). CA19-9 and CEA were determined with a cobas E601 system (Roche, Mannheim, Germany). After surgery, patients were regularly followed up by an outpatient clinic and telephone interview with general examinations such as liver functions, tumor markers and abdominal ultrasound were conducted every 2-3 months during the first year, then 3-6 months from the second year. Abdominal computed tomography or magnetic resonance imaging was further conducted if patients were suspected of having tumor recurrence. The time of OS was defined as the interval from the date of initial diagnosis of $\mathrm{GBC}$ to death or last follow-up.

This study was performed as a retrospective study and complied with the standards of the Helsinki Declaration and current ethical guideline and was approved by the Institutional Ethical Board of West China Hospital of Sichuan University. The patients or patients' families were informed about the purpose of the study and written consent was obtained from the patients or patients' families. In this study, no specific personal information was disclosed, and we ensured that anonymity was maintained.

\section{Statistical Analysis}

SPSS version 25.0 (IBM SPSS Statistics 25.0) was used for statistical analysis. Continuous variables were expressed as the median (range) and categorical variables were expressed as number (percentage). Differences of continuous variables between groups were compared by Student's $t$-test or Mann-Whitney $U$-test. Differences of categorical variables between groups were compared by Pearson's $X^{2}$ test or Fisher's exact probability test. Receiver operating characteristic (ROC) curve was used to identify the optimal cutoff value of PDW. The OS rate was estimated by Kaplan-Meier method and differences between subgroups were analyzed by the Log rank test. Meanwhile, Univariate analysis was performed to assess the prognostic relevance of clinicopathological factors. The multivariate Cox regression proportional hazard model was used to evaluate the significant variables in univariate analysis. $\mathrm{P}<0.05$ was considered statistically significant.

\section{Results}

The clinicopathological features of the patients were presented in Table 1. Among the 303 patients, the median age was 62 years (range 33-85 years). Of these patients, 203 patients $(67.0 \%)$ were female and 100 patients $(33.0 \%)$ were male. The numbers of patients with cholelithiasis, pre-operative biliary drainage, incidental GBC, lymphadenectomy, vascular invasion, perineural invasion, tumor poor differentiation, R0 resection, and postoperative adjuvant therapy were $146(48.2 \%), 30(9.9 \%), 76(25.1 \%)$, 278 (91.7\%), 55 (18.2\%), 59 (19.5\%), 146 (48.2\%), 243 
Table I Baseline Characteristics of Patients with GBC According to PDW Levels

\begin{tabular}{|c|c|c|c|c|}
\hline Variables & Total $(n=303)$ & $\begin{array}{c}\text { PDW } \leq 14.95 \\
(n=|4|)\end{array}$ & $\begin{array}{c}\text { PDW }>14.95 \\
(n=162)\end{array}$ & $\begin{array}{l}P \text { - } \\
\text { value }\end{array}$ \\
\hline Age, years (range) & $62(33-85)$ & $62(33-85)$ & $63(38-85)$ & 0.870 \\
\hline Gender (\%) & & & & 0.064 \\
\hline Female & $203(67.0)$ & $102(72.3)$ & $101(62.3)$ & \\
\hline Male & $100(33.0)$ & $39(27.7)$ & $61(37.7)$ & \\
\hline Cholelithiasis (\%) & & & & 0.200 \\
\hline Absent & $157(5 \mathrm{I} .8)$ & $67(47.5)$ & $90(55.6)$ & \\
\hline Present & $146(48.2)$ & $74(52.5)$ & $72(44.4)$ & \\
\hline TB, umol/L (range) & $12.4(4.0-287.3)$ & $12.7(4.7-287.3)$ & II.8 (4.0-279.1) & 0.197 \\
\hline ALT, IU/L (range) & $23(6-842)$ & $23(6-842)$ & $23(9-842)$ & 0.847 \\
\hline AST, IU/L (range) & $24(13-850)$ & $25(13-850)$ & $24(13-850)$ & 0.922 \\
\hline ALB, g/L (range) & $41.0(26.4-52.4)$ & $41.0(30.2-51.4)$ & $40.9(26.4-52.4)$ & 0.351 \\
\hline WBC, $\times 10^{9} / \mathrm{L}$ (range) & $6.13(2.42-16.43)$ & $5.92(2.42-15.01)$ & $6.29(2.95-16.43)$ & 0.021 \\
\hline PLT, $\times 10^{9} / \mathrm{L}$ (range) & $205(23-480)$ & $210(74-480)$ & $199(23-476)$ & 0.027 \\
\hline NLR (range) & $2.74(0.87-13.95)$ & $2.85(0.92-12.50)$ & $2.59(0.87-13.95)$ & 0.797 \\
\hline PLR (range) & I36.84 (13.86-798.08) & $153.53(44.62-798.08)$ & $125.86(\mid 3.86-476.54)$ & 0.008 \\
\hline PNI (range) & $46.8(30.2-64.2)$ & $47.4(30.2-64.2)$ & $46.2(31.0-61.4)$ & 0.881 \\
\hline CAI9-9, U/mL (range) & $23.23(0.1->1000)$ & $22.48(0.1->1000)$ & $24.47(0.1->1000)$ & 0.071 \\
\hline CEA, U/mL (range) & $2.81(0.27->1000)$ & $2.74(0.27->1000)$ & $2.90(0.28->1000)$ & 0.524 \\
\hline Pre-operative biliary drainage (\%) & & & & 0.327 \\
\hline Absent & $273(90.1)$ & $124(87.9)$ & $149(92.0)$ & \\
\hline Present & $30(9.9)$ & $17(12.1)$ & $13(8.0)$ & \\
\hline Surgical procedures (\%) & & & & 0.781 \\
\hline Simple cholecystectomy & $25(8.3)$ & $13(9.2)$ & $12(7.4)$ & \\
\hline Extent of hepatectomy & & & & \\
\hline Wedge resection & $46(15.2)$ & $24(17.0)$ & $22(13.6)$ & \\
\hline Segment $\mathrm{IVb}$ and $\mathrm{V}$ resection & $163(53.8)$ & $75(53.2)$ & $88(54.3)$ & \\
\hline Right trisegmentectomy & $19(6.3)$ & $7(5.0)$ & $12(7.4)$ & \\
\hline Right hemihepatectomy & $50(16.5)$ & $22(15.6)$ & $28(17.3)$ & \\
\hline Pancreatoduodenectomy (\%) & & & & 0.457 \\
\hline Absent & $287(94.7)$ & I 35 (95.7) & $152(93.8)$ & \\
\hline Present & $16(5.3)$ & $6(4.3)$ & $10(6.2)$ & \\
\hline Hepatic artery reconstruction (\%) & & & & 0.689 \\
\hline Absent & $284(93.7)$ & $133(94.3)$ & I5I (93.2) & \\
\hline Present & $19(6.3)$ & $8(5.7)$ & II (6.8) & \\
\hline Portal-vein reconstruction (\%) & & & & 0.855 \\
\hline Absent & $285(94.1)$ & I $33(94.3)$ & $152(93.8)$ & \\
\hline Present & $18(5.9)$ & $8(5.7)$ & $10(6.2)$ & \\
\hline $\begin{array}{l}\text { Adjacent organs resection (Colon/Stomach/duodenum) } \\
\text { (\%) }\end{array}$ & & & & 0.582 \\
\hline Absent & $284(93.7)$ & $|3|(92.9)$ & $153(94.4)$ & \\
\hline Present & $19(6.3)$ & $10(7.1)$ & $9(5.6)$ & \\
\hline Incidental gallbladder carcinoma (\%) & & & & 0.218 \\
\hline Yes & $76(25.1)$ & $40(28.4)$ & $36(22.2)$ & \\
\hline No & $227(74.9)$ & I0I (7I.6) & $126(77.8)$ & \\
\hline
\end{tabular}

(Continued) 
Table I (Continued).

\begin{tabular}{|c|c|c|c|c|}
\hline Variables & Total $(n=303)$ & $\begin{array}{c}P D W \leq 14.95 \\
(n=\mid 4 I)\end{array}$ & $\begin{array}{c}\text { PDW }>14.95 \\
(n=162)\end{array}$ & $\begin{array}{l}P \text { - } \\
\text { value }\end{array}$ \\
\hline Lymphadenectomy (\%) & & & & 0.567 \\
\hline Absent & $25(8.3)$ & $13(9.2)$ & $12(7.4)$ & \\
\hline Present & $278(91.7)$ & $128(90.8)$ & $150(92.6)$ & \\
\hline No. of retrieved Lymph nodes [range] & $5(1-18)$ & $5(1-18)$ & $5(1-18)$ & 0.796 \\
\hline No. of positive Lymph nodes [range] & $3(1-14)$ & $2(1-13)$ & $3(1-14)$ & 0.673 \\
\hline Vascular invasion (\%) & & & & 0.531 \\
\hline Absent & $248(81.8)$ & $118(83.7)$ & $130(80.2)$ & \\
\hline Present & $55(18.2)$ & $23(16.3)$ & $32(19.8)$ & \\
\hline Perineural invasion (\%) & & & & 0.250 \\
\hline Absent & $244(80.5)$ & $118(83.7)$ & $126(77.8)$ & \\
\hline Present & $59(19.5)$ & $23(16.3)$ & $36(22.2)$ & \\
\hline Tumor differentiation (\%) & & & & 0.138 \\
\hline Well/moderate & $157(5 \mid .8)$ & $80(56.7)$ & $77(47.5)$ & \\
\hline Poor & I $46(48.2)$ & $61(43.3)$ & $85(52.5)$ & \\
\hline T stage $(\%)$ & & & & 0.052 \\
\hline TI & $18(5.9)$ & $9(6.4)$ & $9(5.6)$ & \\
\hline $\mathrm{T} 2$ & $120(39.6)$ & $67(47.5)$ & $53(32.7)$ & \\
\hline T3 & $125(4 \mid .3)$ & $50(35.5)$ & $75(46.3)$ & \\
\hline $\mathrm{T} 4$ & $40(13.2)$ & $15(10.6)$ & $25(15.4)$ & \\
\hline $\mathrm{N}$ stage (\%) & & & & 0.049 \\
\hline No & 145 (47.9) & $76(53.9)$ & $69(42.6)$ & \\
\hline $\mathrm{NI} / 2$ & $158(52.1)$ & $65(46.1)$ & $93(57.4)$ & \\
\hline Margin status (\%) & & & & 1.000 \\
\hline Ro & $243(80.2)$ & $113(80.1)$ & $130(80.2)$ & \\
\hline RI & $60(19.8)$ & $28(19.9)$ & $32(19.8)$ & \\
\hline AJCC stage (\%) & & & & 0.019 \\
\hline $\mathrm{I} / \mathrm{II}$ & $109(36.0)$ & $61(43.3)$ & $48(29.6)$ & \\
\hline III/IV & $194(64.0)$ & $80(56.7)$ & II 4 (70.4) & \\
\hline Postoperative adjuvant therapy (\%) & & & & 0.907 \\
\hline Yes & $74(24.4)$ & $34(24.1)$ & $40(24.7)$ & \\
\hline No & $229(75.6)$ & $107(75.9)$ & $122(75.3)$ & \\
\hline
\end{tabular}

Abbreviations: GBC, gallbladder carcinoma; PDW, platelet distribution width; TB, total bilirubin; ALT, alanine aminotransferase; AST, aspartate transaminase; ALB, albumin; WBC, white blood cell count; PLT, platelet; NLR, neutrophil-to-lymphocyte ratio; PLR, platelet-to-lymphocyte ratio; PNI, prognostic nutritional index; CA 19-9, carbohydrate antigen 19-9; CEA, carcinoembryonic antigen; T, tumor depth; N, lymph node; AJCC, American Joint Committee on Cancer.

(80.2\%), and 74 (24.4\%) patients, respectively. According to the TNM classification, the patients were classified as follows: T1 ( $\mathrm{n}=18 ; 5.9 \%), \mathrm{T} 2(\mathrm{n}=120 ; 39.6 \%), \mathrm{T} 3(\mathrm{n}=125$; $41.3 \%)$, T4 ( $n=40 ; 13.2 \%)$; N0 ( $n=145 ; 47.9 \%), \mathrm{N} 1 / 2$ $(\mathrm{n}=158 ; 52.1 \%)$. In terms of the AJCC stage, 109 patients (36.0\%) were stage I/II and 194 patients (64.0\%) were stage III/IV. The median of TB, ALT, AST, ALB, WBC,
PLT, NLR, PLR, CA19-9, CEA, the number of retrieved and positive lymph nodes were $12.4 \mathrm{umol} / \mathrm{L}$ (range 4.0 287.3umol/L), 23IU/L (range 6-842IU/L), 24IU/L (range 13-850IU/L), 41.0g/L (range 26.4-52.4g/L), $6.13 \times 10^{9} / \mathrm{L}$ (range $\left.2.42-16.43 \times 10^{9} / \mathrm{L}\right), 205 \times 10^{9} / \mathrm{L} \quad$ (range $23-$ $480 \times 10^{9} / \mathrm{L}$ ), 2.74 (range 0.87-13.95), 136.84 (range 13.86-798.08), 46.8 (range 30.2-64.2), 23.23U/mL 
(0.1->1000U/mL), $2.81 \mathrm{U} / \mathrm{mL}(0.27->1000 \mathrm{U} / \mathrm{mL}), 5$ (118 ) and 3 (1-14), respectively. For surgical procedures, the resections were simple cholecystectomy in 25 patients $(8.3 \%)$, cholecystectomy with hepatic wedge resection in 46 patients $(15.2 \%), \mathrm{IVb}$ and $\mathrm{V}$ liver segmentectomy in 163 patients $(53.8 \%)$, right trisegmentectomy in 19 patients $(6.3 \%)$, right hemihepatectomy in 50 patients (16.5\%). In addition, pancreatoduodenectomy, hepatic artery reconstruction, portal-vein reconstruction, and Adjacent organs resection (Colon/Stomach/duodenum) were performed in 16 patients $(5.3 \%), 19$ patients $(6.3 \%), 18$ patients $(5.9 \%)$ and 19 patients $(6.3 \%)$, respectively.

The optimal cutoff value of PDW was 14.95, which was identified by ROC curve analysis. The sensitivity and specificity of PDW in OS were $62.4 \%$ and $67.8 \%$ (AUC $=0.637,95 \%$ confidence interval (CI): 0.570-0.704, $\mathrm{P}<0.001$ ), respectively (Figure 1). Among the 303 patients, 141 patients $(46.5 \%)$ had $\mathrm{PDW} \leq 14.95$ and 162 patients (53.5\%) had PDW $>14.95$.

The relationship between clinicopathological characteristics and PDW was presented in Table 1. There was no significant difference in age, gender, cholelithiasis, TB, ALT, AST, ALB, NLR, PNI, CA19-9, CEA, preoperative biliary drainage, surgical procedures, incidental GBC, lymphadenectomy, the number of retrieved and positive lymph nodes, vascular invasion, perineural invasion, tumor differentiation, $\mathrm{T}$ stage, margin status, and postoperative adjuvant therapy between the $\mathrm{PDW} \leq 14.95$ group and the $\mathrm{PDW}>14.95$ group $(\mathrm{P}>0.05)$. However, we found significant differences in WBC, PLT, PLR, N stage, and AJCC stage between the two groups $(\mathrm{P}<0.05)$.

In this cohort, the 1-, 3-, and 5-year OS were $60.6 \%$, $30.9 \%, 17.3 \%$, respectively (Figure 2A). Moreover, the 1-, 3 -, and 5-year OS of $\mathrm{PDW} \leq 14.95$ group and $\mathrm{PDW}>14.95$ group were $72.0 \%, 41.6 \%, 24.8 \%$ and $51.4 \%, 22.3 \%$, $11.6 \%$, respectively. Comparison of postoperative survival time between the two groups showed statistical significance $(\mathrm{P}<0.001$, Figure $2 \mathrm{~B})$.

Univariate and multivariate Cox analysis were performed to identify the factors that could impact the survival of GBC patients (Table 2). In the univariate analysis, PDW, NLR, PLR, CA19-9, incidental GBC, vascular

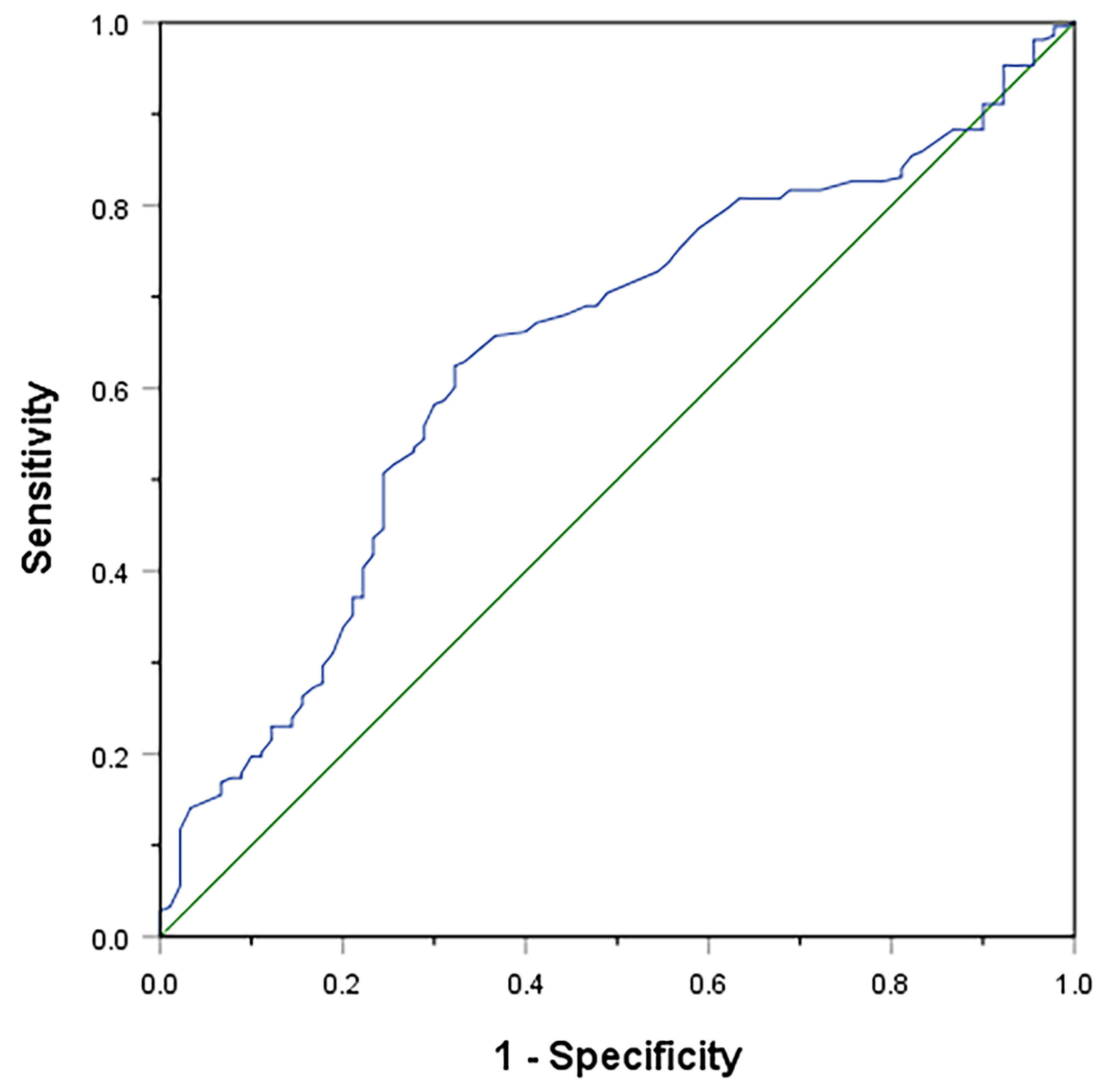

Figure I Optimal cut-off value for the PDW was identified by ROC curve analysis. 

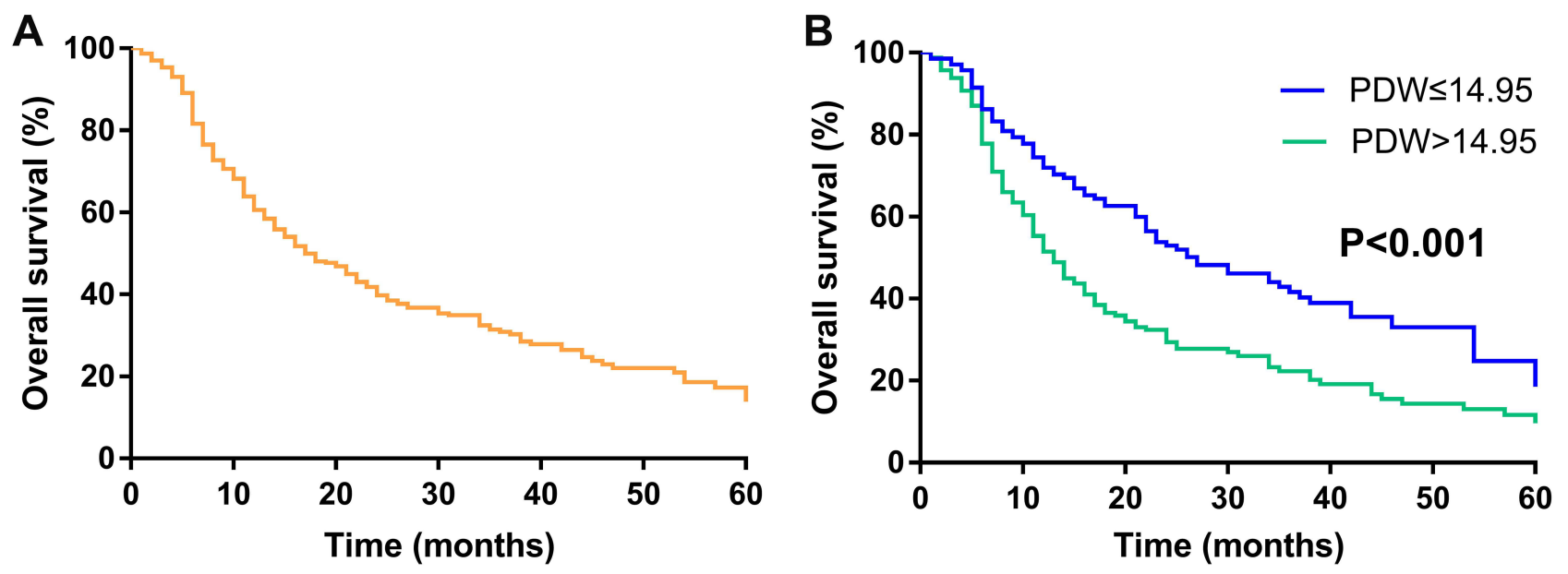

Figure 2 Kaplan-Meier overall survival curves of patients with GBC. (A) Overall survival of 303 patients with GBC. (B) comparing survival outcomes between the PDW $\leq 14.95$ group and PDW>14.95 group.

invasion, perineural invasion, tumor differentiation, $\mathrm{T}$ stage, $\mathrm{N}$ stage, and margin status were significant prognostic factors $(\mathrm{P}<0.05)$. Then, all the factors in univariate analysis with $\mathrm{P}<0.05$ were included in multivariable Cox regression model. The multivariate analysis indicated that PDW (hazard ratio $(\mathrm{HR})=1.976,95 \% \mathrm{CI}$ : 1.474-2.650, $\mathrm{P}<0.001), \quad \mathrm{PLR} \quad(\mathrm{HR}=1.894, \quad 95 \% \quad \mathrm{CI}: \quad 1.406-2.550$, $\mathrm{P}<0.001)$, incidental GBC $(\mathrm{HR}=0.370$, 95\% CI: $0.250-$ 0.547, $\mathrm{P}<0.001)$, tumor differentiation $(\mathrm{HR}=1.344,95 \%$ CI: $1.010-1.790, \mathrm{P}=0.043)$, T stage $(\mathrm{HR}=1.496,95 \% \mathrm{CI}$ : 1.024-2.185, $\mathrm{P}=0.037), \mathrm{N}$ stage $(\mathrm{HR}=2.034,95 \% \mathrm{CI}$ : $1.440-2.873, \mathrm{P}<0.001)$, and margin status $(\mathrm{HR}=1.753$, 95\% CI: $1.241-2.477, \mathrm{P}=0.001$ ) were independent prognostic factors in the patients with GBC.

\section{Discussion}

As we know, our study is the first study to explore the correlation between PDW and prognosis in patients with GBC. In this study, we found that elevated PDW is significantly associated with WBC, PLT, PLR, N stage, and AJCC stage. Moreover, PDW, PLR, incidental GBC, tumor differentiation, $\mathrm{T}$ stage, $\mathrm{N}$ stage, and margin status were independent prognostic factor in GBC patients.

Despite advances in diagnosis and treatment, the 5-year OS rate of GBC still remains poor. ${ }^{4,5}$ In addition, GBC has a high recurrence rate and is insensitive to chemotherapy and radiotherapy. ${ }^{6}$ Hence, identifying novel prognostic factors is clinically urgently needed. Activated platelets mediate tumor growth, invasion, aberrant angiogenesis, and metastasis. ${ }^{10,11}$ There is a complex interaction between tumor cell-induced platelet activation and platelet-induced tumor growth. ${ }^{24}$ In previous studies, it has been reported that there are altered indicators of platelet activation in patients with tumor, such as $\beta$ thromboglobulin ( $\beta$-TG), CD40 ligand, and soluble P-selectin. ${ }^{25-27}$ However, these parameters were not routinely used. PDW reflects changes in platelet size and further reflects platelet activity. ${ }^{19}$ A better point is that PDW is easy-to-detect indicators in routine blood tests. In addition, previous studies demonstrated that PDW is a prognostic risk factor in pancreatic adenocarcinoma, hepatocellular carcinoma, and colon cancer. ${ }^{20-22}$ In our study, we found similar results with most literatures. The elevated PDW is associated with poor prognosis in GBC.

Currently, the molecular mechanisms that explain the correlation between PDW and the prognosis of patients with GBC are poorly understood. Dysfunction of bone marrow cells (including megakaryocytes) may contribute to altering PDW. PDW is a measure of platelet heterogeneity caused by heterogeneous demarcation of megakaryocytes. ${ }^{28}$ Recent studies have demonstrated that granulocytes colony stimulating factor (G-CSF), macrophage colony stimulating factor (M-CSF), and interleukin-6 (IL-6) can regulate megakaryocytic maturation, platelet size and platelet production. ${ }^{29}$ The cytokines of G-CSF and M-CSF secreted by tumor cells could facilitate megakaryopoiesis and subsequent thrombopoiesis in cancer. ${ }^{30}$ In addition, IL-6 is an important proinflammatory cytokine in the tumor microenvironment that promotes tumor angiogenesis, metastasis, and metabolism. ${ }^{31}$ Moreover, local inflammation plays a critical role in the tumor microenvironment. Several proinflammatory 
Table 2 Univariate and Multivariate Analysis of Overall Survival in Patients with GBC

\begin{tabular}{|c|c|c|c|c|c|c|}
\hline \multirow[b]{2}{*}{ Variables } & \multicolumn{3}{|c|}{ Univariate Analysis } & \multicolumn{3}{|c|}{ Multivariate Analysis } \\
\hline & HR & $95 \% \mathrm{Cl}$ & $\mathbf{P}$ & HR & $95 \% \mathrm{Cl}$ & $\mathbf{P}$ \\
\hline Age, years $(>62$ versus $\leq 62)$ & 0.871 & $0.664-1.141$ & 0.316 & & & \\
\hline Gender (female versus male) & 0.911 & $0.686-1.209$ & 0.518 & & & \\
\hline Cholelithiasis (absent versus present) & 1.213 & $0.925-1.590$ & 0.163 & & & \\
\hline $\mathrm{TB}$, umol/L $(>12.4$ versus $\leq 12.4)$ & 1.037 & $0.792-1.359$ & 0.790 & & & \\
\hline ALT, IU/L (>23 versus $\leq 23)$ & 1.066 & $0.813-1.397$ & 0.645 & & & \\
\hline AST, IU/L (>24 versus $\leq 24)$ & 1.242 & $0.948-1.628$ & 0.115 & & & \\
\hline ALB, $g / L(>4 I .0$ versus $\leq 4 I .0)$ & 0.775 & $0.589-1.018$ & 0.067 & & & \\
\hline WBC, $\times 10^{9} / \mathrm{L}(>6.13$ versus $\leq 6.13)$ & 1.233 & $0.940-1.617$ & 0.130 & & & \\
\hline PLT, $\times 10^{9} / \mathrm{L}(>205$ versus $\leq 205)$ & 1.106 & $0.845-1.448$ & 0.463 & & & \\
\hline PDW $(>14.95$ versus $\leq 14.95)$ & 1.796 & $1.357-2.376$ & $<0.001$ & 1.976 & $1.474-2.650$ & $<0.001$ \\
\hline NLR $(>2.74$ versus $\leq 2.74)$ & 1.576 & I.199-2.070 & 0.001 & 1.157 & $0.869-1.542$ & 0.317 \\
\hline PLR $(>136.84$ versus $\leq 136.84)$ & 2.229 & $1.680-2.957$ & $<0.001$ & 1.894 & $1.406-2.550$ & $<0.001$ \\
\hline $\mathrm{PNI}(>46.8$ versus $\leq 46.8)$ & 0.922 & $0.701-1.212$ & 0.559 & & & \\
\hline $\mathrm{CA} 19-9, \mathrm{U} / \mathrm{mL}(>23.23$ versus $\leq 23.23)$ & 1.736 & $1.318-2.285$ & $<0.001$ & 1.283 & $0.949-1.735$ & 0.106 \\
\hline $\mathrm{CEA}, \mathrm{U} / \mathrm{mL}(>2.8 \mathrm{I}$ versus $\leq 2.8 \mathrm{I})$ & 1.286 & $0.982-1.684$ & 0.068 & & & \\
\hline Pre-operative biliary drainage (absent versus present) & 1.315 & $0.864-2.000$ & 0.201 & & & \\
\hline IGBC (absent versus present) & 0.302 & $0.211-0.431$ & $<0.001$ & 0.370 & $0.250-0.547$ & $<0.001$ \\
\hline Vascular invasion (absent versus present) & 1.704 & $1.220-2.381$ & 0.002 & 1.302 & $0.914-1.854$ & 0.144 \\
\hline Perineural invasion (absent versus present) & 1.515 & $1.092-2.102$ & 0.013 & 1.132 & $0.804-1.595$ & 0.478 \\
\hline Tumor differentiation (well/moderate versus poor) & 1.626 & $1.235-2.141$ & 0.001 & 1.344 & $1.010-1.790$ & 0.043 \\
\hline $\mathrm{T}$ stage $(\mathrm{TI} / 2$ versus $\mathrm{T} 3 / 4)$ & 3.576 & $2.602-4.915$ & $<0.001$ & 1.496 & $1.024-2.185$ & 0.037 \\
\hline $\mathrm{N}$ stage ( $\mathrm{N} 0$ versus $\mathrm{NI} / 2$ ) & 3.400 & $2.502-4.620$ & $<0.001$ & 2.034 & I.440-2.873 & $<0.001$ \\
\hline Margin status ( $R 0$ versus $R I$ ) & 2.497 & $1.786-3.492$ & $<0.001$ & 1.753 & I.24I-2.477 & 0.001 \\
\hline Postoperative adjuvant therapy (yes versus no) & 1.194 & $0.877-1.626$ & 0.259 & & & \\
\hline
\end{tabular}

Abbreviations: GBC, gallbladder carcinoma; HR, hazard ratio; $\mathrm{Cl}$, confidence interval; TB, total bilirubin; ALT, alanine aminotransferase; AST, aspartate transaminase; ALB, albumin; WBC, white blood cell count; PLT, platelet; PDW, platelet distribution width; NLR, neutrophil-to-lymphocyte ratio; PLR, platelet-to-lymphocyte ratio; PNI, prognostic nutritional index; CA 19-9, carbohydrate antigen 19-9; CEA, carcinoembryonic antigen; AJCC, American Joint Committee on Cancer.

cytokines, such as IL-1, IL-6, IL-8, IL-12, IL-18, tumor necrosis factor (TNF), and interferon- $\gamma(\mathrm{IFN}-\gamma)$, induce the maturation of heterogenic megakaryocytic maturation, resulting in the production and the release of immature platelets in the circulatory system. ${ }^{32}$ Another potential mechanism is that platelets facilitate the hypercoagulable state in the tumor microenvironment. ${ }^{8}$ Activated platelets enable tumor cells to cover themselves with platelets and escape the immune defense attacks. ${ }^{33}$

As previously reported, ${ }^{6}$ we found the poor tumor differentiation, advanced $\mathrm{T}$ stage, lymph node metastasis, and positive resection margin predict poor prognosis in GBC patients. ${ }^{34}$ In addition, our study demonstrated that PLR was an independent prognostic factor in GBC patients. The similar result was reported by Pang et al. ${ }^{35}$ They pointed out that PLR $\geq 117.7$ was independently associated with poor survival in GBC. Moreover, the multivariate Cox analysis indicated that incidental GBC was independent prognostic factor in patients with GBC. The patients with incidental
GBC had a relatively better survival than those with suspected GBC. The similar results were reported by Mazer et al. $^{36}$ In the study conducted by Mazer et al ${ }^{36}$ they compared incidental and suspected GBC and found pre-operative suspicion was a strong risk factor when controlling for operation extent, tumor differentiation, $\mathrm{T}$ stage, and other factors.

The present study has several limitations. First, our study was a single-center retrospective study with a relatively small number of patients. Second, the patients were composed of Chinese, and whether the results were applicable to other races remains to be verified. Finally, this study lacked of molecular mechanistic of the correlation between PDW and the prognosis of patients with GBC. Additional large-scale, multicenter prospective trials are needed to further verify the reliability of our results.

In conclusion, elevated PDW can predict poor prognosis in GBC patients, and further studies are needed to verify the reliability of our results and clarify the exact molecular mechanistic of PDW in GBC. 


\section{Author Contributions}

All authors made a significant contribution to the work reported, including in the conception, study design, execution, acquisition of data, analysis and interpretation, or in all of these areas. All authors also took part in drafting, revising, and critically reviewing the article, and gave final approval of the version to be published. All authors have agreed on the journal to which the article be submitted, and agree to be accountable for all aspects of the work. Fei Liu and Hai-Jie $\mathrm{Hu}$ contributed equally to this work and should be considered co-first authors.

\section{Funding}

This work was supported by Sichuan Science and Technology Program (2018JY0019), the Fundamental Research Funds for the Central Universities (2019SCUH), Wu Jieping Medical Foundation for Clinical Research (320.2710.1825), and Post-Doctor Research Project, West China Hospital, Sichuan University (2019HXBH025).

\section{Disclosure}

The authors declare that they have no conflicts of interest. All authors listed have read the complete manuscript and have approved submission of the paper.

\section{References}

1. Siegel R, Ma J, Zou Z, Jemal A. Cancer statistics, 2014. CA Cancer J Clin. 2014;64(1):9-29. doi:10.3322/caac.21208

2. Ito H, Matros E, Brooks DC, et al. Treatment outcomes associated with surgery for gallbladder cancer: a 20-year experience. World J Gastrointest Surg. 2004;8(2):183-190. doi:10.1016/j.gassur.2003.10.006

3. Puhalla H, Wild T, Bareck E, et al. Long-term follow-up of surgically treated gallbladder cancer patients. Eur J Surg Oncol. 2002;28 (8):857-863. doi:10.1053/ejso.2002.1301

4. Butte JM, Matsuo K, Gönen M, et al. Gallbladder cancer: differences in presentation, surgical treatment, and survival in patients treated at centers in three countries. J Am Coll Surg. 2011;212(1):50-61. doi:10.1016/j.jamcollsurg.2010.09.009

5. Cziupka K, Partecke LI, Mirow L, et al. Outcomes and prognostic factors in gallbladder cancer: a single-centre experience. Langenbecks Arch Surg. 2012;397(6):899-907. doi:10.1007/s00423-012-0950-8

6. Bartlett DL, Fong Y, Fortner JG, Brennan MF, Blumgart LH. Longterm results after resection for gallbladder cancer. Implications for staging and management. Ann Surg. 1996;224(5):639-646. doi:10.1097/00000658-199611000-00008

7. Sharma D, Brummel-Ziedins KE, Bouchard BA, Holmes CE. Platelets in tumor progression: a host factor that offers multiple potential targets in the treatment of cancer. J Cell Physiol. 2014;229(8):1005-1015. doi: $10.1002 /$ jcp. 24539

8. Li N. Platelets in cancer metastasis: to help the "villain" to do evil. Int J Cancer. 2016;138(9):2078-2087. doi:10.1002/ijc.29847

9. Buergy D, Wenz F, Groden C, Brockmann MA. Tumor-platelet interaction in solid tumors. Int $J$ Cancer. 2012;130(12):2747-2760. doi:10.1002/ijc.27441
10. Mezouar S, Frère C, Darbousset R, et al. Role of platelets in cancer and cancer-associated thrombosis: experimental and clinical evidences. Thromb Res. 2016;139:65-76. doi:10.1016/j. thromres.2016.01.006

11. Bambace NM, Holmes CE. The platelet contribution to cancer progression. J Thromb Haemost. 2011;9(2):237-249. doi:10.1111/ j.1538-7836.2010.04131.x

12. Li FX, Wei LJ, Zhang H, Li SX, Liu JT. Significance of thrombocytosis in clinicopathologic characteristics and prognosis of gastric cancer. Asian Pac J Cancer Prev. 2014;15(16):6511-6517. doi:10.7314/apjcp.2014.15.16.6511

13. Chadha AS, Kocak-Uzel E, Das P, et al. Paraneoplastic thrombocytosis independently predicts poor prognosis in patients with locally advanced pancreatic cancer. Acta oncol. 2015;54(7):971-978. doi:10.3109/0284186x.2014.1000466

14. Josa V, Krzystanek M, Eklund AC, et al. Relationship of postoperative thrombocytosis and survival of patients with colorectal cancer. Int J Surg. 2015;18:1-6. doi:10.1016/j.jisu.2015.03.005

15. Życzkowski M, Prokopowicz G, Taborowski P, et al. Basic parameters of blood count, serum sodium, and creatinine as prognostic factors for renal cell carcinoma at five-year follow-up. Med Sci Monit. 2018;24:3895-3902. doi:10.12659/msm.906867

16. Feng Z, Wen H, Bi R, Duan Y, Yang W, Wu X. Thrombocytosis and hyperfibrinogenemia are predictive factors of clinical outcomes in high-grade serous ovarian cancer patients. BMC Cancer. 2016;16 (1):43. doi:10.1186/s12885-016-2070-2

17. Wang RT, Zhang LQ, Mu YP, et al. Prognostic significance of preoperative platelet count in patients with gallbladder cancer. World $J$ Gastroenterol. 2015;21(17):5303-5310. doi:10.3748/wjg.v21. i17.5303

18. Seretis C, Youssef H, Chapman M. Hypercoagulation in colorectal cancer: what can platelet indices tell us? Platelets. 2015;26 (2):114-118. doi:10.3109/09537104.2014.894969

19. Mahdavi-Zafarghandi R, Shakiba B, Keramati MR, Tavakkoli M. Platelet volume indices in patients with varicocele. Clin Exp Reprod Med. 2014;41(2):92-95. doi:10.5653/cerm.2014.41.2.92

20. Liu P, Zhu Y, Liu L. Elevated pretreatment plasma D-dimer levels and platelet counts predict poor prognosis in pancreatic adenocarcinoma. Onco Targets Ther. 2015;8:1335-1340. doi:10.2147/ott.S82329

21. Zuo X, Kong W, Feng L, Zhang H, Meng X, Chen W. Elevated platelet distribution width predicts poor prognosis in hepatocellular carcinoma. Cancer Biomark. 2019;24(3):307-313. doi:10.3233/cbm182076

22. Sakin A, Sahin S, Sakin A, et al. Mean platelet volume and platelet distribution width correlates with prognosis of early colon cancer. J BUON. 2020;25(1):227-239.

23. Regimbeau JM, Fuks D, Bachellier P, et al. Prognostic value of jaundice in patients with gallbladder cancer by the AFC-GBC-2009 study group. Eur J Surg Oncol. 2011;37(6):505-512. doi:10.1016/j. ejso.2011.03.135

24. Tesfamariam B. Involvement of platelets in tumor cell metastasis. Pharmacol Ther. 2016;157:112-119. doi:10.1016/j. pharmthera.2015.11.005

25. Ay C, Simanek R, Vormittag R, et al. High plasma levels of soluble P-selectin are predictive of venous thromboembolism in cancer patients: results from the Vienna Cancer and Thrombosis Study (CATS). Blood. 2008;112(7):2703-2708. doi:10.1182/blood-2008$02-142422$

26. Al-Mondhiry H. beta-Thromboglobulin and platelet-factor 4 in patients with cancer: correlation with the stage of disease and the effect of chemotherapy. Am $J$ Hematol. 1983;14(2):105-111. doi:10.1002/ajh.2830140202

27. Huang J, Jochems C, Talaie T, et al. Elevated serum soluble CD40 ligand in cancer patients may play an immunosuppressive role. Blood. 2012;120(15):3030-3038. doi:10.1182/blood-2012-05-427799 
28. Paulus JM. Recent advances in the story of megakaryocyte physiology. Pathologie-Biologie. 1981;29(3):133-135.

29. Kaushansky K. Growth factors and hematopoietic cell fate. A New Feature: Controversies in Hematology . Blood. 1998;92(2):345.

30. Kowanetz $\mathrm{M}, \mathrm{Wu} \mathrm{X}$, Lee J, et al. Granulocyte-colony stimulating factor promotes lung metastasis through mobilization of Ly6G+Ly6C + granulocytes. Proc Natl Acad Sci U S A. 2010;107 (50):21248-21255. doi:10.1073/pnas.1015855107

31. Kumari N, Dwarakanath BS, Das A, Bhatt AN. Role of interleukin-6 in cancer progression and therapeutic resistance. Tumour Biol. 2016;37(9):11553-11572. doi:10.1007/s13277-016-5098-7

32. Huang Y, Cui MM, Huang YX, et al. Preoperative platelet distribution width predicts breast cancer survival. Cancer Biomark. 2018;23 (2):205-211. doi:10.3233/cbm-181267

33. Franco AT, Corken A, Ware J. Platelets at the interface of thrombosis, inflammation, and cancer. Blood. 2015;126(5):582-588. doi:10.1182/ blood-2014-08-531582
34. Roa I, Ibacache G, Muñoz S, de Aretxabala X. Gallbladder cancer in Chile: pathologic characteristics of survival and prognostic factors: analysis of 1366 cases. Am J Clin Pathol. 2014;141(5):675-682. doi:10.1309/ajcpqt3eln2bbcka

35. Pang Q, Zhang LQ, Wang RT, et al. Platelet to lymphocyte ratio as a novel prognostic tool for gallbladder carcinoma. World $J$ Gastroenterol. 2015;21(21):6675-6683. doi:10.3748/wjg.v21. i21.6675

36. Mazer LM, Losada HF, Chaudhry RM, et al. Tumor characteristics and survival analysis of incidental versus suspected gallbladder carcinoma. World J Gastrointest Surg. 2012;16(7):1311-1317. doi:10.1007/s11605-012-1901-y

\section{Publish your work in this journal}

Cancer Management and Research is an international, peer-reviewed open access journal focusing on cancer research and the optimal use of preventative and integrated treatment interventions to achieve improved outcomes, enhanced survival and quality of life for the cancer patient.
The manuscript management system is completely online and includes a very quick and fair peer-review system, which is all easy to use. Visit http://www.dovepress.com/testimonials.php to read real quotes from published authors. 